concluding summary. Nordgren and Westrin begin their collection by referring to a recent paradigm shift within a number of disciplines which involves a recognition of the existence of altruism and an interest in understanding it. The diversity of the collection is splendid, with perspectives drawn from psychology, Darwinian theory, economics and biomedical ethics as well as public health. But, for me, this same diversity has made the collection as a whole unsatisfying even though it contains some accomplished essays. In a longer book, and perhaps one written after the experience of sharing these papers, there would have been scope for dialogue and debate to open up the substantive and epistemological conflicts and resonances between the various perspectives.

As it stands the collection is multidisciplinary rather than interdisciplinary. The authors not only occupy different theoretical frameworks and ask rather different questions but they also work with significantly different conceptions of altruism.

Some of the contributors are concerned with operationalising and measuring altruism. For them it is part of the tool-kit of social and experimental psychology, and has to be defined as precisely as possible and independently of the evaluative dimensions of ordinary usage. Here there is a tendency to start with the reductionist egoism - altruism dichotomy and to look for ways to define these terms and to detect the differences between them. C Daniel Batson reports on his ingenious experiments to discern people's "underlying motivation", rather than their merely instrumental goals, and on his discovery of "genuine altruism" in his experimental subjects. At the end of his paper he is careful to explain that, in addition to egoism and altruism, there are other forms of "prosocial motivation" including what he labels collectivism ("not me or thee but we") and principlism. Batson thereby limits the label altruism to cases in which the "underlying motive" is to benefit others rather than to cases where motivation encompasses, or results in, the wellbeing of others.

By contrast Thomas Murray, in what I see as the most successful and insightful contribution, starts by rejecting "the simplistic dichotomy between self-interest and altruism" in favour of "the complexity of motivations we seem to find in actual human cultures". His is a discussion of gift-giving between both friends and strangers, and includes an exploration of analogies between Trobriand Islanders' customs and practices and those of modern health care systems in general, and the practices of blood and organ donation in particular. But his analysis and celebration of solidarity, and of the ways in which we are motivated to affirm our relationships and not just our selves, is perhaps closer to what Batson describes as collectivism: “... humans are often self-seeking, to be sure, but ... they must attend to the needs of others. In doing so, they also contribute to their own flourishing. Whether we choose to call that altruism is not so important" (page 77).

What both of these authors share is the advocacy, albeit in different terms, of more complex models of motivation than those which underlie many currents in both social science and policy-making. Indeed one of the clear themes in the volume is a scepticism about "homo economicus" and the increasing influence of associated market models in Western European health policy. Through their scepticism these papers point to an important research programme which is beyond the scope of this collection: there is a need to map the models of motivation, and the assumptions about specific motivations, that underpin health care policies and practices and to seek to understand how certain forms of motivation are produced, sustained or inhibited. Most urgently, there is a need to challenge public policies which are based on simple assumptions about self-interested motivation, as these assumptions have the potential to be harmful as well as misguided.

In this connection it is worth reading Anthony Culyer's excellent piece, Altruism and economics. Here Culyer makes it clear that economics as a discipline can deal with more complex accounts of motivation than is implied by some uses of "homo economicus", and reminds us that, for example, a picture of agents as utility maximisers should not be equated with a picture of agents as selfish. Of course agents only pursue things which they regard as valuable. It is this which facilitates the all too common charge of universal egoism. Yet valued things can be very different; they can be more or less individualistic and - in most useful senses of the term - more or less self-seeking.

ALAN CRIBB

Centre for Public Policy Research, King's College London
IVF in the 90s. Towards a Medical, Social and Ethical Evaluation

Edited by E Hildt and D Mieth, Aldershot, Hants, Ashgate Publish- ڤ્ ing, 1998, 370 pages, $£ 45$ (hc).

Some books are more frustrating $\overrightarrow{\mathrm{E}}$ read than others, and read one mustaf one is committed to write a comment for the fournal of Medical Ethics. Frustrating because the potential for $N_{0}$ much is there, and the sum total is wanting. One must admit, howeve् that the sub-title, Towards a Medicdt Social and Ethical Evaluation, does ngt necessarily lead the reader to expect-8 conclusion on the subject matter. The book concerns IVF and its cons quences, especially from the point of view of "the particular connectiog with genetic diagnosis and therapyo (this being the remit of this European Commission supported endeavour).

But does this book accomplish tasks? When evaluating, one must 1 . some foundations, some plan of actio and this is where the frustration lie One feels strongly that an analysis, the extraction of the spirit of the contribs tions by the editors would have madecompletely different book. The prefa does not attempt any such analysis and introduces the subject by a me listing. Worse, to a specialist in the field, it makes the strange stateme that the success rate of IVF has be challenged compared with the occur rence of spontaneous pregnancy, when in fact the editors probably refer to윽 paper comparing unexplained inferti ity of relatively short duration and to value of fertility treatments in general challenge anyone to explain to me how a woman with surgically irremediable tubal damage may conceive withop IVF bar a miracle. It would be too east to highlight the scientific inaccuracies which sprinkle the text of some contif butions. This is not my purpose here

It must be stressed, however, that such bad communication between dife ferent disciplines may be at the core of what is described by $\mathrm{P}$ van Tongere as the "antagonism" he often observe between scientists and ethicists. This differs from my personal experience, as a clinician who teaches ethics to he medical students, and who thus may claim to have feet in both camps.

Indeed they should not be seen camps, especially for the practitioners amongst us, but as overlapping fields in 
our relationship as carers. So if there is one lesson to be learnt from this book, it is that of Levinas (quoted in another chapter by van Tongeren), not so much the relationship between desire (and to limit the alternative of an ethics of desire to one of rights [W Lesch] is a simplistic reduction) and immortality (although the psychoanalyst might argue that we seek immortality through begetting children). Levinas asserts that entering into a relation with the other by looking into his or her face, ie getting to know him or her, means accepting the differences with love, rather than with the antagonistic approach surmised to be so general.

What about the structure of this book? The introduction contains a contribution by the "father of IVF", Professor R G Edwards, in his usual clear and enlightening style, but also the evermore irritating assertion of the reduction of the complaint "infertility" to a social construct rather than a disease. The right questions about interdisciplinary discourse are asked by $\mathrm{D}$ Mieth and would have been better placed at the beginning, as would some of the clear scientific contributions by Cooke and Lieberman. The order of the parts is also in some disarray: if the title suggests "towards" a medical, social and ethical evaluation, it would have been logical to follow this in three different parts: I, Infertility could have been the medical/scientific basis (Edwards, Cooke, Lieberman) or part of the introduction, and included indications (part III), as well as part V (chances and, risks) and even its limits (part X). The social element with some of the excellent psychological contributions (Schmidt, Englert, and the account by a couple of patients) could well have been coupled with the part of the book on counselling, which has an interesting paper on multicultural settings, which brings us to the bioethics of Engelhardt, although he is not mentioned.

All this might leave part III, the final part, for the ethical contributions, and the evaluation promised in the title. That the status, legal and moral, of the embryo should be tackled (again) is not out of place as it is indeed at the root of many dilemmas in IVF. But that it should be done without any reference to developments in Europe (and outside) whether legal or otherwise, (for instance a three-day meeting on this very subject was held at the Council of Europe in December 1996) is very frustrating, especially for a publication with a European background.
Indeed one expects such an endeavour to start from a basis of widely read, previously published literature if only to criticise it and progress.

Finally let us concentrate on some of the "ethics" contributions: Mieth's criticism of the fallacies to avoid is interesting. They are described as empirical, motivational and genetic, but unfortunately no system is positively recommended. Some titles are misleading, for instance the "ethical considerations concerning alternative treatments to IVF" is more in the realm of deconstructive sociology than ethics, but the chapter by Haker at least mentions beneficence (good life??), and concern for the other as concepts, although sadly wanting in detailed analysis of either. Freedom of action is mentioned by Hildt, with an interesting aside on "unavoidability". The debate around human dignity and human rights is interesting but the notion of dignity and its use is indeed more international than purely German, as it forms the basis of several international codes, including the UNESCO declarations, against the background of Locke, Kant and Schopenhauer.

In short, too many parts, and much too many short contributions contribute to the sense of lack of purpose. But this book should not be ignored, even if found wanting and repeating many arguments heard and published elsewhere (for instance, the splendid contribution by Ines de Beaufort on research on "surplus" embryos in the Strasbourg meeting mentioned above). We therefore look forward to the next publication, as such European Union programmes tend to span three years, and to a final report, edited with care, which would synthesise what I am sure will eventually be a satisfactory contribution to one of the most exciting fields (medically, socially and ethically speaking) at the end of this century and into the next.

FRANCOISE SHENFIELD

Clinical Lecturer in Infertility, University College Hospital, London

\section{Intersections:Women on Law, Medicine and Technology}

Edited by Kerry Peterson, Aldershot, Ashgate/Dartmouth, 1997, 246 pages, $£ 39.50$.

Developments in technology in health care practice have been accomplished with what some may regard as fright- ening, and others as exhilarating, speed over recent years. These developments have the potential at least for the enhancement of medical power, as the doctor is increasingly the creator of life and a means by which life may be brought to an end. This has been accompanied by a perceived need for medical power to be the subject both of review and of regulation. In the introduction to Intersections: Women on Law, Medicine and Technology, Peterson states that the aim of the volume is to "dissect medical power and examine alternative approaches to current practices as a means of reframing the issues and establishing principled foundations for the future". This is underpinned also by a goal: to "achieve a balance between the competing goals of public interest and human rights". The collection contains an interesting range of perceptive essays discussing the operation of medical power over a series of areas. The discussion ranges from reproductive issues, as in Bennett's essay, Gamete donation, reproductive technology and the law, which focuses upon the question of gamete donation in the Australian context, to the withdrawal of treatment at the end of life, as in McLean's essay, Letting die or assisting death: how should the law respond to the patient in the persistent vegetative state?, which examines policy considerations post Bland. Human rights considerations in the context of the incompetent patient are examined in the essay of Jones and Marks, Female and disabled: a human rights perspective on law and medicine. Historical perspectives on the debate are provided, for example by Mitchinson's essay, It's not society that's the problem, it's women's bodies: a historical view of medical treatment of women and Britton's, Hippocrates: dead or alive?, exploring the Hippocratic Oath.

Today any discussion of medical power inevitably encompasses a vast range of issues, all human life is indeed there. Any volume dissecting medical power is thus, by its very nature, highly selective. It would have been helpful had the rationale for the selection of the issues and themes examined in the volume been highlighted at the start of the collection, with the links between the essays identified. While Peterson does pull together certain themes/issues which emerge from the collection in her thought-provoking final essay, Dissecting medical power, I suggest a better approach would have been either for the collection to have begun with this essay, or for there to have been a 